\title{
Growth of the cross border space in the northwest of Mexico: the challenges for its sustainable development
}

\author{
A. Ranfla-González ${ }^{1}$, R. Rojas-Caldelas ${ }^{2}$, O. Villegas-Olivar ${ }^{1}$ \\ \& C. R. García-Flores ${ }^{2}$ \\ ${ }^{I}$ Social Sciences Research Institute, \\ University Autonomous of Baja California, Mexico \\ ${ }^{2}$ Faculty of Architecture, University Autonomous of Baja California, \\ Mexico
}

\begin{abstract}
Baja California and Sonora, located in northwestern Mexico, function as a socioeconomic space to the bordering states and cities of California and Arizona. Since 1999, the Federal, and the Baja California and Sonora Governments, have promoted a touristic corridor in Mar de Cortes and a new alternative port in the Pacific, in the south of Baja California, for the trade between the USA and China. These new actions will have an impact on the fragile natural environment and on the population settled at the south of both Mexican states. This work studies the projects, evaluates their impact on the natural and social environment of the region and sets a scenario of the socioeconomic and future territorial organization networks in a sustainable framework. The methodology consists of an analysis of the socioeconomic profiles of the areas receiving the projects, evaluates the environmental, economic and social impact of the infrastructure projects and the main actions through an environmental impact matrix, projecting the probable demographic and territorial scenario that is conditioned to the maintenance of an environmental equilibrium, the restructuring of economic activities and the compensating actions for the most vulnerable population.
\end{abstract}

Keywords: sustainable development, regional planning, regional environment assessment, infrastructure networks. 


\section{Introduction}

Historically the northwest of México - particularly the states of Baja California and Sonora - due to their location far away from the political and economic center of the country had a late territorial integration. In contrast, this region established an early relationship with the southwestern region of the USA, in particular with the most dynamic states of this country during the 20th century, California and Arizona. During this past century, the economic relations and the social interactions of the states Baja California and Sonora were increased and were a determining factor for the present economic growth. The dynamism of the regional economy explains the quick demographical growth experienced by the urban population of the two entities, which increased from $74.4 \%$ to $89.7 \%$ during the 1970-2005 period [1] and was materialized with the quick growth registered by the cities of Tijuana, Mexicali, San Luis Rio Colorado and Nogales during that period. Since the postwar era and after the signing of the North American Free Trade Agreement (NAFTA) in 1994, the manufacturing activity of Baja California and Sonora destined for world trade registered a significant increase - in both states in 2004, 19.5\% of the total plants for exports in Mexico and $13.8 \%$ of the total personnel were engaged in these activities [2]. The foregoing data confirm the evolution of the economies of Baja California and Sonora have had in the global production network and they also explain a regional trend of concentrating the population in the urban agglomerations of their northern border because of the connection they have with the USA network of highways and communications infrastructure.

By taking advantage of their vicinity to the USA, and with California and Arizona in particular, during the 1990s an emerging movement was produced to impulse the activities and economic expectations of the two Mexican states. This trend was sustained in the increment of the group of retired USA citizens known as the "baby boomer" generation, distinguished by their credit capacity, which activated the real-estate markets and touristic activities in the southeast of the USA, and also Baja California and Sonora in their littorals of Mar de Cortes and the Pacific [3]. Almost a decade later the expansion experienced through the China-USA trade created economic expectations in the south of Baja California, finding in Punta Colonet the possibility of constructing a new port as part of the strategy of the new Mexican multimodal gateways corridors in the Pacific, as a response to the saturation of the west cost ports of the USA [4]. Both aspects gave rise to independent projects promoted by the Federal Government, the National Fund for Tourism, and the Baja California and the Sonora Governments who proposed actions in the various zones of the territory in these two states, to impulse the economic growth in a large region that, because of its natural conditions, infrastructure and equipment, had been left at the margin.

The three main development projects (Multimodal Punta Colonet-San Luis Río Colorado Corridor, San Felipe-Bahia de los Angeles Corridor and GuaymasSan Luis Río Colorado Corridor) for the two states are aimed at promoting the growth of the southern part of these two states. This region is characterized by the fragility of its natural environment, the lack of economic activities and a 
scarce population, as well as a high social vulnerability that urges the development of the region with a sustainable approach, such as that proposed by the Federal Government programs (Escalera Náutica of Mar de Cortés and the National Program of Infrastructure 2007-2012) [5]. The natural conditions and the existing laws at a federal level require that for the promotion of economic growth in the territories of the south of Baja California and Sonora, these states should be linked with their more developed regions and that a sustainable approach is undertaken. In practice, each individual initiative has shown that there is lack of coordination with the other projects, that the proposed actions are out of time, and that there are contradictions in the proposed calendars. This work is aimed at identifying such inconsistencies and sets out an integrated functionality framework for all the zones of the projects, approaching them as a finite ecosystem [6] and finding the right solutions.

\section{Methodology}

The accomplishment of projects with the view of attaining the growth of economical zones that are actually depressed or barren in southern Baja California and Sonora poses at least two challenges for planning a sustainable development: 1) to maintain the stability of the natural capital of the region, the nearctic deserts strip in particular, with a higher desertification vulnerability [7] and 2) to maintain the adequate and controlled management of a regional demographic dynamics to avoid an even greater lack of infrastructure and public services in the region where these projects are to be carried out.

The purpose of this work is to make an assessment of the zones where the projects are located, evaluate their impact in the natural and economic-social environment, and set out the scenario of the probable territorial and socioeconomic organization networks, if the proposed actions take place. For this purpose, a delimitation was made through a geographic information system of the impacted zones for the proposed project to generate a database for the region with 40 variables produced by the Mexican National Institute of Geography, Statistics, and Information (INEGI) [8]. This will address three themes: i) population and its distribution; ii) connectivity networks (by air, roads and ocean); and iii) access to infrastructure and public services.

Once these areas were delimitated and analyzed, each of the projects' scenarios were studied as to settlement, investments, actions, timetables and the expected impact in the economical, environmental and social areas. The assessment of the project and the relevant actions were made by applying an adapted version of the Leopold matrix to evaluate the impact of each of the actions contemplated for the three projects [9]. Thirteen matrixes were prepared, one for each sub-zone of the three projects (see Figure 1). The matrix prepared for each action sets the hierarchy of each action in respect of the impact considered by a group of experts regarding the environment and the economical and social areas. For the environment, the following factors were considered: loss of vegetal coverage; habitat destruction (animal life); protected species; relief transformation; loss of productive soils; soil erosion; air pollution; soil 
contamination; and water pollution. For the social aspects, the following factors were considered: population density; housing; tenancy; education; health; public security; urban facilities; water and drainage; electrical power; waste disposal; traffic; transportation; and culture. Finally, for the economic aspects, the following factors were considered: employment; income; primary sector; secondary sector; tertiary sector and tax collection.

Based on the results of the assessment of environmental, social and economical impacts, three probable scenarios of demographic growth were projected: Of these three, the most probable scenario was considered the one integrating independent actions among the projects. This scenario was defined in contrast with the unlimited growth concept proposed individually by the projects. From this assumption, three fundamental conditions were defined in the proposed scenario: 1) more moderate growth rates for the region were estimated; 2) it was considered that, due to the natural environment, the region will maintain the trend of concentrating the population in urban areas; and 3) it was considered that the realization of the proposed projects for the region would create new integration axes with a more dense territorial pattern. This assessment, the evaluation and the proposed scenario are synthesized in this paper.

\section{Results}

The results of the work are presented in three sections: assessment of the zones of the project; evaluation of environmental, economical and social impacts; and a probable demographic and territorial scenario.

\subsection{Assessment of the zones of the project}

The environmental aspects in the zone of impact of the proposed projects are determining. The zone is located in the strip of arid zones of Mexico, characteristic for its low precipitation levels and the scarcity of superficial and subterranean hydrological resources. The degree of desertification vulnerability in the project zones has been estimated at $75 \%$, especially in the coast of the Pacific Ocean and Mar de Cortes. For this reason the Federal Government promoted and instrumented the Ecological Land Use Management of Mar de Cortes and the Escalera Náutica Program [10]. In both instruments the highest fragility levels were identified in small areas on the coast of Mar de Cortes, in the Kino, Guaymas, Puerto Peñasco, Delta del Colorado, San Luis Gonzaga, Bahía de los Ángeles areas, and in the Pacific in the Tijuana-Ensenada Corridor.

In terms of environmental stability levels, Baja California reaches approximately $70 \%$ of its territory and the critical zones are linked to the production areas and population settlements in the north of the state. As for Sonora, with the exception of the natural reserve El Pinacate and Gran Desierto de Altar in the border with Baja California, the rest is unstable. The balance stresses the existence of a natural capital potential in the zones of the project for a regulated utilization, which requires the assessment of the environmental 
impact and observance of the existing land and maritime ecological regulation for the zones involved in the project [10]. A critical theme for human settlements and the economic activities in the zones of impact of the projects is the limited resources of water and energy in practically the entire territory of Baja California and Sonora, a condition that is integrated in each one of the projects.

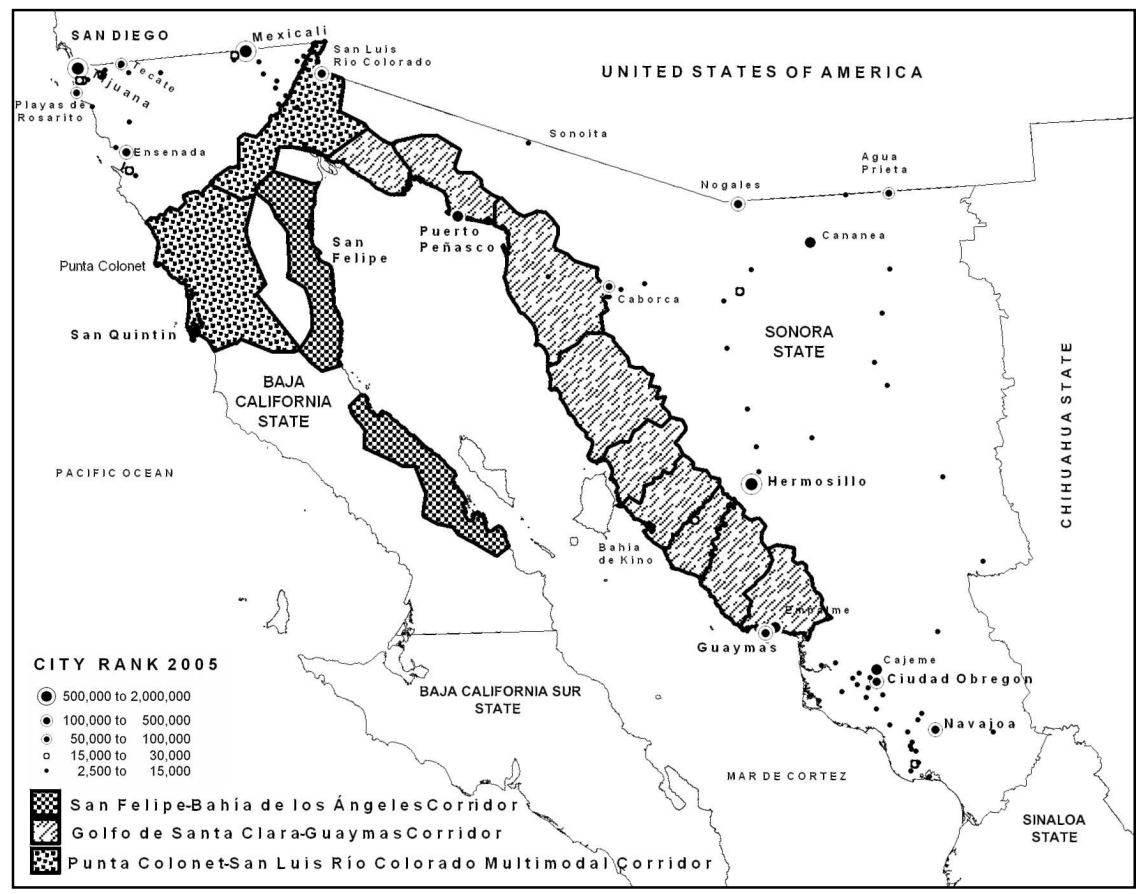

Source: Sedesol-UABC; 2007 [9]

Figure 1: $\quad$ Zones of the regional growth projects.

For the socioeconomic analysis the three projects were divided into $13 \mathrm{sub}$ zones (see Figure 1) showing differences in the rhythms of demographic growth, highlighting the growth of larger agglomerations and stagnation in rural regions during the 2000-2005 period. The average growth by region was: Puerto Peñasco (7.21\%); Golfo de Santa Clara (2.89\%); Punta Colonet (2.18\%); San Felipe-Puertecitos (1.78\%); San Agustín (1.07\%); San Luis Río Colorado $(0.63 \%)$ and Guaymas $(0.48 \%)$. As for the volume of population, the main locations at present are: Guaymas, Puerto Peñasco, San Luis Río Colorado, San Felipe, and the emerging ones, Punta Colonet, Vicente Guerrero, Lázaro Cárdenas, San Quintín and Miguel Alemán.

In economic terms these 13 sub-zones concentrate the employment in primary activities and services; mainly the rendering of touristic services in scattered locations. The foregoing justifies the concern of the Sonora government to reactivate the economy of the south and give support to touristic services as an alternative to regional growth. Puerto Peñasco and Golfo de Santa Clara are an 
example to justify this purpose. In Baja California this pressure is lower in the southern regions that have a moderate migratory flow.

In general, the two states have low economic activities in the zones where the proposed projects are to impact. The situation is socially more complex in Sonora, because the new projects are aimed at achieving an interregional and sector restructuring, reducing the present population expulsion. In contrast, the economic expansion to new territories in Baja California could become a new source to impulse migration to such an entity.

\subsection{Evaluation of the environmental, economic and social impacts}

Based on the data that resulted from the adapted Leopold matrix for each one of the sub-zones, the following is a summary of the results for the three projects, of the estimated impacts in the environmental, economic and social subject matters.

\section{A. Multimodal Punta Colonet-San Luis Río Colorado Corridor}

This project has been planned in an integral manner and its realization will radically transform the present territorial structure of Baja California and Sonora. The economic impact of the various actions has the higher valuations because of the volume of employment generation and the impulse to diversify. The valuation of the social impact is high because the actions are to elevate the access parameters and the quality of services currently available for the population in the impacted zones. If the estimations of the project are complied with, the demographic growth is moderate. With regard to its environmental impact, it is negative because of the loss of vegetal coverage, destruction of the habitat, water, soil and air contamination, and to a lesser extent, erosion of the soil and relief transformation requiring mitigation measures vis-à-vis the realization of the project.

\section{B. San Felipe-Bahia de los Angeles Corridor}

In practice this project has moderate investment and action volumes in comparison with the other two projects. The main proposed action is the construction of the four-lane highway Mexicali-San Felipe, realization of which has been slow. The environmental impact of this project also has a negative evaluation, since the growth of population as the economic activities on the littoral are conditioned to a low impact use of the soil; consequently, the actions are being concentrated in the main agglomerations. In view of the economic and social stagnation the region actually has, both aspects registered high evaluations.

\section{Guaymas-San Luis Río Colorado Corridor}

The corridor is conformed by eight specific zones located along the coastal strip. Twenty-four actions for the infrastructure, equipment, real-estate development and tourism are contemplated. From the total, there are 14 actions with a high impact at a regional and local level. The project has as a main purpose the reactivation of the economy at Guaymas-Empalme that has been in stagnation since 1990. There is also a proposal for the integration of the extensive territory 
in the littoral of Mar de Cortés articulating Guaymas-Empalme, Puerto Peñasco and San Luis Río Colorado in a 403 miles (650 kilometers) extension.

To activate the economy of the region, the program proposes actions for the connectivity, infrastructure and equipment that will impel new real estate and touristic developments, where valuations are high in this aspect. In the social impact, the proposed actions are aimed at a betterment of the population's life conditions in the main agglomerations by increasing their access to electricity, water-drainage and transportation. The risk of the project is that it generates high expectations that may catalyze the migration and deteriorate the conditions of the population density, housing, education, health, public safety, urban facilities and traffic. Regarding the environment, the effects are negative; therefore we propose a strategy of consolidating the main agglomerations and better coordination in the development of the rural communities.

In synthesis, the three projects have a negative environmental impact and the evaluation of positive impacts in the economic and social themes. The dimensions and complexity of the projects are very different; nevertheless, the impacts in Baja California and Sonora require coordination between the two states to take advantage of the synergy in benefit of a better management of the environment.

\subsection{Possible scenario}

From the diagnosis of the different components and the evaluation of the proposed actions for the three projects in the zones of impact, we intended to set out the possible scenarios associated with the expected changes. For this task, we established two phases. In the first one we identified three probable scenarios: the tendency, under the assumption of an absence of changes in the zones of impact in Baja California and Sonora, the second one, that maintained as assumption the estimation of the three projects - unlimited growth criterion -, and the third scenario, with a possible assumption estimating integrated growth of the three projects, with a moderate demographic increase to which the economic, social and environmental variables were adjusted in the zones of the projects.

This last scenario proposed sustainable economic growth in the region guided by three strategic axes: to attain a greater equilibrium in the regional-urban distribution of the population and the economic activities; to have a greater efficiency in the intra and interregional connectivity, and to develop the compensatory actions to restrict the inequalities provoked by the projects. The specific conditions to attain these proposals are subject to the compliance of several conditions as follows.

Demographic. The interregional demographic dynamism is very sensible to the occupancy expectations among the various regions. If the proposed projects are carried out, this would send signals to the regional work markets, thus catalyzing migratory flows. It is desirable that the entities promoting the projects may promote, regulate and administer the population interregional flows and limit the destabilization caused by the projects in their regional environment. 
Economic. In general, the demand expected to be attended with the realization of the projects is foreign, therefore the global climate for business is a determining factor for their instrumentation and the continuity of the promotion and performance tasks. Also, the acting of the leadership of public and private actors that have promoted and organized the projects shall be a determining factor. A very important effort has to be made with the Mar de Cortes projects, having a greater atomization of the actors and the public and private entities that promote it. For the Multimodal Punta Colonet Corridor, the demand for services is important, since part of the main investors are foreigners; therefore it is critical to reach agreements between foreign and national investors, and the federal government in the public deed of January 2010.

Social. It is important to carry out strategic actions to reduce the negative impact in the life conditions of the most sociably vulnerable population in three critical aspects: access to water and drainage services, improvement of housebuilding materials, and giving attention to homes having a monthly income under 100 US dollars.

Environmental. The particularities found in the extensive zones of the projects should be solved by means of a strategy that seeks equilibrium in the distribution of the rural-urban population [11]. The larger agglomerations should be consolidated, such as Guaymas, Puerto Peñasco, San Luis Río Colorado and San Felipe, and adequate planning should be made for the new Punta Colonet city. Attention should be given to settlements of less than 2,000 inhabitants with poor services, by means of a strategy for their concentration. Most of these settlements are within the land or maritime protected natural areas; therefore, they offer potential for their exploitation and a sustainable administration [12].

Consequently, with the foregoing criteria we have presented a geographic projection in Figure 2 showing the impact of the three projects in the territory, the possible restructuring of networks and the orientation towards a new regional topology in view of the realization of the three proposed projects, as well as demographic growth and territorial structure projections.

\section{Conclusions}

From the analysis, the evaluation and the probable scenario of the three regional projects promoted by the federal government and the governments of Baja California and Sonora during the last decade, we could identify three challenges to achieve a sustainable development of the region: managing the complexity of the instrumentation of this kind of projects for their financing, planning and procedures; to overcome the difficulties in attaining a coordination of the three projects and among the involved actors in order to advance the proposed transformations, and finally, surmount the difficulties in maintaining continuity in the purpose of impelling the economic growth in the south of the two states, and at the same time, promote the valuation of the natural capital conformed by the littoral of Mar de Cortes. 


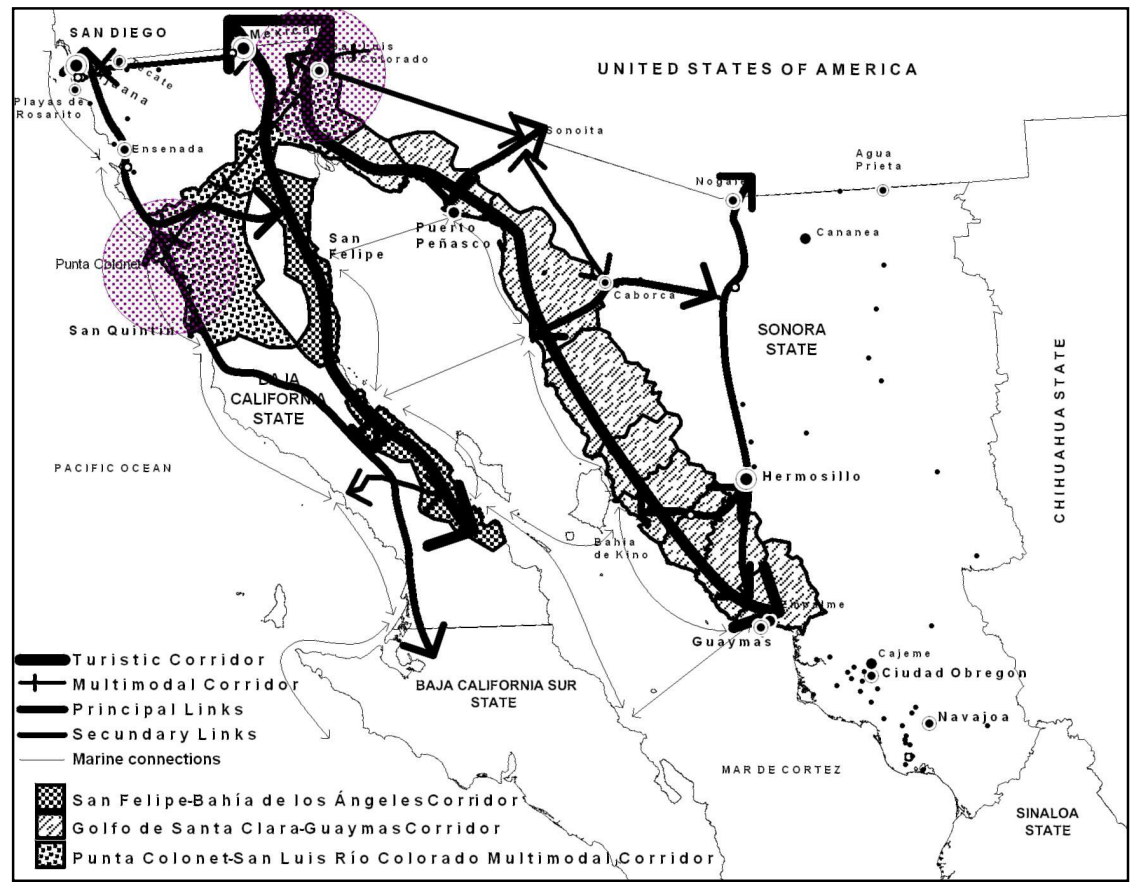

Source: Sedesol-UABC; 2007 [9]

Figure 2: $\quad$ Probable scenario and potential networks.

\section{References}

[1] Instituto Nacional de Geografía, Estadística e Informática (INEGI), http://www.inegi.gob.mx/

[2] Presidencia de la República, Quinto Informe de Gobierno, México, 2005

[3] BBVA Bancomer, (2007). Mercado Inmobiliario para Baby Boomers. Revista Situación Inmobiliaria, Septiembre, México, pp. 16-22, 2007

[4] Vickerman, J., Global Trade Trends Impacts on North American Ports, Transystems, Northfolk, 2007

[5] Secretaria del Medio Ambiente y Recursos Naturales (SEMARNAT), Ordenamiento Ecológico de la Región de Mar de Cortés. México, 2003; Presidencia de la República, Programa Nacional de Infraestructura 20072012, http://www.infraestructura.gob.mx

[6] Daly H.E., From Adjustment to Sustainable Development: The obstacle of Free Trade, in Beyond Growth: The Economics of Sustainable Development, Beacon Press, Boston, 158-167, 1996

[7] Oropeza-Orozco,O., Evaluacion a la vulnerabilidad a la desertificacion, Instituto Nacional de Ecologia, Mexico, 1995, http://www.ine.gob.mx/veajei/publicaciones/libros/437/oropeza.html 
[8] Instituto Nacional de Geografía, Estadística e Informática (INEGI), XII Censo General de Población y Vivienda 2000 y II Conteo de Población y Vivienda, 2005

[9] SEDESOL-UABC (2007), Desarrollo Regional Proactivo en el Noroeste, México, D.F.

[10] Fondo Nacional de Fomento al Turismo (FONATUR). Escalera Náutica del Mar de Cortés, México, 136 pp.,2003; Secretaria del Medio Ambiente y Recursos Naturales (SEMARNAT), Ordenamiento Ecológico de la Región de Mar de Cortés. México, 2003

[11] Harris, J.M., Population and Urbanization, in Harris J.M., et AL, (eds) A Survey of Sustainable Development, Social and Economic Dimensions, Island Press, Washington, pp. 115-130(2001)

[12] Fossati, A., Panella, G., Tourism and sustainable development: A theoretical framework, in Fossati, A., Panella, G., (eds), Tourism and Sustainable Economic Development, Kluwer Academic Publisher, BostonLondon, 3-36, 2002 